\title{
Physiological Mechanisms of Drought Resistance in Four Native Ornamental Perennials
}

\author{
Douglas S. Chapman and Robert M. Augé \\ Department of Ornamental Horticulture and Landscape Design, University of Tennessee, Knoxville, \\ TN 37901-1071 \\ Additional index words. beebalm, coneflower, Echinacea purpurea, Helianthus angustifolius, Monarda didyma, osmotic \\ adjustment, Rudbeckia fulgida var. Sullivantii, stomatal conductance, sunflower, water relations
}

\begin{abstract}
Understanding physiological drought resistance mechanisms in ornamentals may help growers and landscapers minimize plant water stress after wholesale production. We characterized the drought resistance of four potted, native, ornamental perennials: purple coneflower [Echinacea purpurea (L.) Moench], orange coneflower [Rudbeckia fulgida var. Sullivantii (Beadle \& Boynt.) Cronq.], beebalm (Monarda didyma L.), and swamp sunflower (Helianthus angustifolius L.). We measured a) stomatal conductance of leaves of drying plants, b) lethal water potential and relative water content, and c) leaf osmotic adjustment during the lethal drying period. Maintenance of stomatal opening as leaves dry, low lethal water status values, and ability to osmotically adjust indicate relative drought tolerance, with the reverse indicating drought avoidance. Echinacea purpurea had low leaf water potential $\left(\psi_{\mathrm{L}}\right)$ and relative water content $(\mathrm{RWC})$ at stomatal closure and low lethal $\psi_{\mathrm{L}}$ and RWC, results indicating high dehydration tolerance, relative to the other three species. Rudbeckia fulgida var. Sullivantii had a similar low $\psi_{\mathrm{L}}$ at stomatal closure and low lethal $\psi_{\mathrm{L}}$ and displayed relatively large osmotic adjustment. Monarda didyma had the highest $\psi_{\mathrm{L}}$ and RWC at stomatal closure and an intermediate lethal $\psi_{\mathrm{L}}$, yet displayed a relatively large osmotic adjustment. Helianthus angustifolius became desiccated more rapidly than the other species, despite having a high $\psi_{\mathrm{L}}$ at stomatal closure; it had a high lethal $\psi_{\mathrm{L}}$ and displayed very little osmotic adjustment, results indicating relatively low dehydration tolerance. Despite differences in stomatal sensitivity, dehydration tolerance, and osmotic adjustment, all four perennials fall predominantly in the drought-avoidance category, relative to the dehydration tolerance previously reported for a wide range of plant species.
\end{abstract}

Water is the earth's most abundant compound, yet lack of water is the single most important resource limiting plant distribution and productivity throughout the world (McWilliam, 1986; Turner and Kramer, 1980). Plants have evolved various physiological and morphological responses (or mechanisms) to endure periods of water stress (Begg, 1980; Levitt, 1980; Morgan, 1980). Identifying droughtresistance responses and their influences on productivity and yield is essential to drought-resistance selection and breeding programs and for developing water-conserving agricultural practices.

Plants that have tissues with low dehydration tolerance and that depend on avoiding water deficits for survival are known as drought avoiders (Ludlow et al., 1983; Turk et al., 1980). Drought avoiders have mechanisms that maximize water uptake, minimize water loss, or combine the two. Drought avoiders typically minimize water loss with stomata that close rapidly with decreases in atmospheric humidity (Nagarajah and Shulze, 1983) or leaf water status (Ludlow and Ibaraki, 1979; Nobel, 1977), or with morphological characteristics such as leaf shedding, reduced leaf size, or deep, extensive root systems (Begg, 1980; Kummerow, 1980). In contrast, plants with tissues that are dehydration tolerant and that have only moderate avoidance mechanisms are known as drought tolerators. These plants rely on osmotic adjustment to survive drought (Ludlow et al., 1985). Osmotic adjustment helps maintain turgor and hence sustains metabolic activity during drought; stomata remain partially open (Flower and Ludlow, 1986; Ludlow, 1980a), and net photosynthesis continues, although at a reduced

Received for publication 11 Feb. 1993. Accepted for publication 26 May 1993. This work was partially supported by a Univ. of Tennessee professional development award to R.M.A. We gratefully acknowledge the technical assistance of Ann Stodola, and we thank Sven Svenson, Bruce Schaffer, Robert Trigiano, Otto Schwarz, and the anonymous reviewer for their efforts in improving the manuscript. The cost of publishing this paper was defrayed in part by the payment of page charges. Under postal regulations, this paper therefore must be hereby marked advertisement solely to indicate this fact. rate (Ackerson and Hebert, 1980). There is a spectrum in response ranging from extreme drought avoidance to extreme drought tolerance, and, although the terms avoidance and tolerance are useful in categorizing drought resistance, not all plants fit closely into one or the other category.

The purpose of this research was to characterize and compare physiological drought-resistance responses of four native, ornamental perennials that are indigenous to contrasting natural habitats. Echinacea purpurea and Rudbeckia fulgida var. Sullivantii grow on open, sunny sites such as meadows and prairies, where dry conditions frequently prevail, whereas Monarda didyma and Helianthus angustifolius usually occur on wetter sites adjacent to streams or bogs (Radford, 1968). The four species are widely cultivated and commercially grown for ornamental use in gardens and landscapes. In this experiment, stomatal behavior, dehydration tolerance, and osmotic adjustment during prolonged soildrying cycles were investigated.

\section{Materials and Methods}

\section{Stomatal behavior experiments}

Plant material and culture. Twenty 4- to 6-week-old seedlings of E. purpurea, R. fulgida var. Sullivantii, M. didyma, and $H$. angustifolius were planted on 5 May 1991 in 8-liter plastic pots (top width $21 \mathrm{~cm}$, bottom width $17 \mathrm{~cm}$, height $25 \mathrm{~cm}$ ) containing a 4 bark : 1 sand medium (v/v) amended with dolomitic lime at 2.0 $\mathrm{kg} \cdot \mathrm{m}^{-3}$, slow-release fertilizer $(20 \mathrm{~N}-1.7 \mathrm{P}-8.3 \mathrm{~K}$; O.M. Scotts and Sons, Marysville, Ohio) at $1.78 \mathrm{~kg} \cdot \mathrm{m}^{-3}$ and soluble trace elements (Peters Fertilizer Products, W.R. Grace, Fogelsville, Pa.) at 0.48 $\mathrm{g} \cdot \mathrm{m}^{-3}$. Medium $\mathrm{pH}$ was 4.7 to 5.0 at transplanting. A water-soluble fertilizer (20N-8.8K-16.6P; Peters) was applied at a rate of 237 mM $\mathrm{N}$ every 7 to 10 days at watering. All plants were grown under natural daylight in a greenhouse in Knoxville, Tenn., and they remained well watered until the drought treatment began. 
Drought treatment and water relations measurements. On 10 July 1991, four plants of each species were arranged randomly on a greenhouse bench, watered, and subsequently subjected to a continuous soil-drying cycle by withholding water from pots. Leaf diffusive conductance (Cs), leaf temperature, photosynthetic photon flux (PPF), leaf water potential $\left(\psi_{\mathrm{L}}\right)$, leaf osmotic potential $\left(\psi_{\pi}\right)$, and leaf relative water content (RWC) were measured on each leaf beginning on day 1 of the soil-drying cycle and continuing until Cs declined to $<0.5 \mathrm{~mm} \cdot \mathrm{s}^{-1}(\approx 7$ to 21 days, depending on species). All measurements were performed daily between 0900 and $1330 \mathrm{HR}$ on healthy, unshaded, recently fully expanded leaves. PPF was measured with each $\mathrm{Cs}$ measurement and ranged from 150 to $900 \mu \mathrm{mol} \cdot \mathrm{m}^{-2} \cdot \mathrm{s}^{-1}$ on sunny days with no supplemental light and from 300 to $750 \mu \mathrm{mol} \cdot \mathrm{m}^{-2} \cdot \mathrm{s}^{-1}$ on cloudy days under supplemental 400-W high-pressure sodium lights (Voigt Lighting Industries, Leonia, N.J.). Preliminary tests indicated that Cs did not change predictably within these diurnal or irradiance ranges. Sodium-vapor lights were used on all cloudy days and were turned on at least $1 \mathrm{~h}$ before measurements began. Leaf temperature ranged from 22 to $34 \mathrm{C}$ and greenhouse relative humidity ranged from $40 \%$ to $75 \%$ during the experiment at the time of porometry measurements. Numbers of leaves sampled per species on each day varied according to daily declines in $\mathrm{Cs}$ and $\psi_{\mathrm{I}}$, such that a wide spectrum of values for $\mathrm{Cs}, \psi_{\mathrm{L}}, \psi_{\pi}$, and RWC could be collected for each species during the drying cycle.

Cs and leaf temperature were measured adjacent to the mid-vein on abaxial leaf surfaces with an automatic-cycling porometer (model AP-4; Delta T Devices, Cambridge, England). PPF was measured for each leaf sample with a quantum sensor (LI-COR, Lincoln, Neb.) attached to a datalogger (model 21X; Campbell Scientific, Logan, Utah). Immediately after determining Cs and leaf temperature, leaf samples were wrapped in plastic cling-film to minimize moisture loss and excised, and $\psi_{\mathrm{L}}$ was determined with a pressure chamber (Soilmoisture Equipment Corp., Santa Barbara. Calif.). Balance points were observed on cut petioles with a microscope. Leaf RWC was determined on leaf tips (2 to $5 \mathrm{~cm}^{2}$ ) excised from the same leaf sample used to determine $\psi_{\mathrm{L}}$ and $\psi_{\pi}$, rehydrated for $4 \mathrm{~h}$ at $4 \mathrm{C}$, and calculated as $\mathrm{RWC}=(\mathrm{FW}-\mathrm{DW}) /$ (SW - DW), where FW, DW, and SW were the fresh weight at excision, dry weight after oven-drying for at least $48 \mathrm{~h}$ at $80 \mathrm{C}$, and saturated weight of leaf tip, respectively. The remainder of the leaf was used to determine $\psi_{\pi}$ immediately after measuring $\psi_{\mathrm{L}}$. The leaf was inserted into a 1 - or 3-ml plastic syringe, frozen in liquid N, and thawed at room temperature for 20 to $60 \mathrm{~min}$. Leaf osmotic potential was determined with a vapor-pressure osmometer (model 5500; Wescor, Logan, Utah), calibrated with a graded series of $\mathrm{NaCl}$ solutions, on sap expressed onto 6-mm filter paper disks. Leaf turgor potential $\left(\psi_{\mathrm{p}}\right)$ was calculated as $\psi_{\mathrm{p}}=\psi_{\mathrm{L}}-\psi_{\pi}$. The experiment was repeated 7 to 24 Aug. 1991 with a new set of plants. The above measurements were made quickly by three investigators working together to minimize water loss from samples. Preliminary tests showed that quickly pressurizing wrapped leaves did not usually depress values of subsequent RWC and $\psi_{\pi}$ measurements more than $\approx 1 \%$.

Experimental design. The experimental design was a $4 \times 2$ (species $\times$ drying cycle) factorial with four replicates for each treatment combination. Since in the analysis of variance (ANOVA) [General Linear Models (GLM) Procedure, SAS, Cary, N.C.] there were no significant species $\times$ drying cycle interactions, results from the two drying cycles were pooled for regression analysis. Pooled standard errors of the means were calculated by taking square roots of the error mean squares and dividing them by the square root of the number of observations in a mean.

\section{Dehydration tolerance and osmotic adjustment experiment}

Plant material and culture. Twelve 4- to 6-week-old seedlings of E. purpurea, R. fulgida var. Sullivantii, M. didyma, and $H$. angustifolius were planted in 20-liter plastic pots (top width $29 \mathrm{~cm}$, bottom width $25 \mathrm{~cm}$, height $29 \mathrm{~cm}$ ) containing a 4 bark : 1 sand medium (v/v) on 7 and 8 June 1991. Medium pH and amendment rates of lime, slow-release fertilizer, and micronutrients were identical to those used for the stomatal behavior experiments. A water-soluble fertilizer (20N-8.8K-16.6P; Peters) was applied at a rate of $237 \mathrm{~mm} \mathrm{~N}$ every 7 to 10 days at time of watering. Plants remained growing in a greenhouse in Knoxville until December 1991, when it was necessary to impose a cold treatment for plants to break dormancy induced by short fall days. After foliage was cut back to 5 to $10 \mathrm{~cm}$ above soil level, plants were placed into refrigeration (12C) on 3 Dec. 1991. On 6 Jan. 1992, plants were moved back into a greenhouse, and irrigation and fertilization were immediately resumed using the same type and rate of watersoluble fertilizer applied previously.

Drought treatment and water relations measurements. On 21 Apr. 1992, plants were randomly arranged on a growing bench, well watered, and subsequently subjected to a slow, continuous soil-drying cycle by withholding water. At the start of soil drying, E. purpurea, $R$. fulgida var. Sullivantii, and $H$. angustifolius plants were about the same height (40 to $60 \mathrm{~cm})$ and width $(25$ to $40 \mathrm{~cm})$ and had 25 to 50 leaves. Monarda didyma was more compact $(\approx 20$ $\mathrm{cm}$ high and $\approx 40 \mathrm{~cm}$ wide) but had more leaves per plant (40 to 100).

Leaf osmotic potential at full turgor $\left(\psi_{\pi}^{100}\right)$ was determined between 1200 and $1300 \mathrm{HR}$ on the first day (day 0 ) of the soil-drying cycle on one leaf from each plant. Procedures for determining $\psi_{\pi}^{100}$ were the same as those used for measuring $\psi_{\pi}$ in the stomatal behavior experiment. To assess $\psi_{\pi}^{100}$ after drought, one leaf per plant was excised at time of sampling for dehydration tolerance (see procedures for lethal measurements below), rehydrated by floating (petiole submerged) on distilled water for $4 \mathrm{~h}$ at $3 \mathrm{C}$, and blotted dry, and $\psi_{\pi}^{100}$ was determined as above. Leaf osmotic adjustment $\left(\Delta \psi_{\pi}{ }^{100}\right)$ was assessed as $\Delta \psi_{\pi}{ }^{100}=\psi_{\pi}{ }^{100(\mathrm{~b})}-\psi_{\pi}{ }^{100(\mathrm{a})}$, where $\psi_{\pi}{ }^{100(\mathrm{~b})}$ and $\psi_{\pi}{ }^{100(\mathrm{a})}=\psi_{\pi}{ }^{100}$ before and after drought, respectively.

Dehydration tolerance of the four species was characterized by measuring lethal leaf $\psi_{\mathrm{L}}$, lethal RWC, and lethal soil water potential $\left(\psi_{\mathrm{s}}\right)$. Dehydration tolerance has been operationally defined as the $\psi_{\mathrm{L}}$ or RWC of the last surviving leaf (called the lethal value) on a plant subjected to a slow, continuous soil-drying cycle (Ludlow, 1989). Plants were checked daily after beginning the drying cycle and lethal measurements begun when only five to six live leaves with minimal necrotic areas ( $<25 \%$ of total leaf area) remained. Sampling was performed between 0800 and $1000 \mathrm{HR}$ beginning on 5 May 1992 and continued until 12 June 1992.

Lethal $\psi_{\mathrm{L}}$ determinations were performed with two thermocouple psychrometers (model SC-10; Decagon Devices, Pullman, Wash.) calibrated daily with a graded series of $\mathrm{NaCl}$ solutions, following standard psychrometer precautions (Oosterhuis and Wullschleger, 1987). Psychrometer sample changers were connected to nanovoltmeter thermometers (model NT-3; Decagon Devices) used to derive temperature and $\mu \mathrm{V}$ readings for conversion into $\psi$ values. Lethal $\psi_{\mathrm{L}}$ was determined on strips cut from leaf laminae adjacent and parallel to mid-veins and placed inside the psychrometer chamber with abaxial sides exposed to the center of sample cups.

Lethal $\psi_{\mathrm{s}}$ values were determined on the same plants from which other lethal values were measured with the thermocouple psychrometers described above on soil samples extracted from the 
root zone, 18 to $25 \mathrm{~cm}$ below the soil surface near the center of the pot. Preliminary tests indicated that leaf and soil samples generally reached thermal and water-vapor equilibrium in the psychrometer chamber in $2 \mathrm{~h}$; all samples were allowed to equilibrate for a minimum of $2 \mathrm{~h}$. Thermocouple psychrometers were used to determine $\psi_{\mathrm{L}}$ in this experiment because the pressure chamber gave inconsistent values at very low $\psi_{L}$ and because psychrometers are not subject to these pressurization errors. Leaf RWC was determined as before on another leaf sample excised from each plant.

Experimental design and statistical analysis. The experiment used a completely randomized design with 10 plants of each species (40 plants total) subjected to one prolonged lethal soildrying cycle. Mean separation of lethal $\psi_{\mathrm{L}}$, lethal $\psi_{\mathrm{s}}$, lethal RWC, $\psi_{\pi}{ }^{100(\mathrm{~b})}, \psi_{\pi}{ }^{100(\mathrm{a})}$, and $\varnothing \psi_{\pi}{ }^{100}$ was performed using ANOVA (GLM, $\mathrm{SAS})$ and Duncan's multiple range test $(P \leq 0.05)$.

\section{Results}

Stomatal behavior. Stomatal conductance decreased in a similar curvilinear manner during the drying cycle in E. purpurea and $R$. fulgida var. Sullivantii, with rapid initial declines slowing below about $-1.50 \mathrm{MPa} \psi_{\mathrm{L}}$ and $3 \mathrm{~mm} \cdot \mathrm{s}^{-1} \mathrm{Cs}$ (Fig. 1a). At high $\psi_{\mathrm{L}}$, Cs of $M$. didyma was about one-fourth that of $H$. angustifolius and $R$. fulgida var. Sullivantii and one-third that of E. purpurea (Fig. 1b). Stomatal conductance of $M$. didyma fell most rapidly at high $\psi_{\mathrm{L}}$, slowing at about $-0.75 \mathrm{MPa} \psi_{\mathrm{L}}$ and $2 \mathrm{~mm} \cdot \mathrm{s}^{-1} \mathrm{Cs}$. Conductance fell more rapidly with declining $\psi_{\mathrm{L}}$ in $H$. angustifolius than in the other three species (Fig. 1b). At about $-1.0 \mathrm{MPa} \psi_{\mathrm{L}}$ and $4 \mathrm{~mm} \cdot \mathrm{s}^{-1} \mathrm{Cs}$, the decline in $\mathrm{Cs}$ began to slow. Conductance measurements in all species stopped when leaves began dying (i.e., when samples were incapable of rehydration for RWC measurements). To get an indication of $\psi_{\mathrm{L}}$ and RWC at or near stomatal closure, we computed mean $\psi_{\mathrm{L}}$ and RWC between 0.5 and $1.5 \mathrm{~mm} \cdot \mathrm{s}^{-1} \mathrm{Cs}$ (Fig. 2), as leaf conductance never became zero. Mean $\psi_{\mathrm{L}}$ near stomatal closure $\left(\psi_{\mathrm{L}}^{\rightarrow 0}\right)$ was lower in E. purpurea $(-2.79 \mathrm{MPa})$ and $R$. fulgida var. Sullivantii $(-2.46 \mathrm{MPa})$ than in $M$. didyma $(-1.21$ $\mathrm{MPa}$ ) and $H$. angustifolius $\left(-1.47 \mathrm{MPa}\right.$ ) (Fig. 2a). The lowest $\psi_{\mathrm{L}}$ reached in $H$. angustifolius and $M$. didyma was 1.0 to $1.5 \mathrm{MPa}$ higher than low values in E. purpurea and R. fulgida var. Sullivantii.

In E. purpurea and R. fulgida var. Sullivantii, Cs fell with decreasing leaf RWC in a similar curvilinear fashion during the soil-drying cycle, with rapid initial declines slowing at $\approx 0.70 \mathrm{~g} \cdot \mathrm{g}^{-}$ ${ }^{1} \mathrm{RWC}$ and $3 \mathrm{~mm} \cdot \mathrm{s}^{-1}$ Cs (Fig. 3a). At high leaf RWC, Cs for $M$. didyma was about one-third as high as Cs for E. purpurea and $R$. fulgida var. Sullivantii and one-fourth as high as for H. angustifolius (Fig. 3b). As leaf RWC declined, Cs fell very little in M. didyma. Conductance in $H$. angustifolius fell rapidly at high leaf RWC, with initial declines slowing at $\approx 0.70 \mathrm{~g} \cdot \mathrm{g}^{-1} \mathrm{RWC}$ and $3 \mathrm{~mm} \cdot \mathrm{s}^{-1} \mathrm{Cs}$. Mean leaf RWC near stomatal closure $\left(\mathrm{RWC}^{\rightarrow 0}\right)$ was lower in $E$. purpurea $\left(0.56 \mathrm{~g} \cdot \mathrm{g}^{-1}\right)$ and $H$. angustifolius $\left(0.47 \mathrm{~g} \cdot \mathrm{g}^{-1}\right)$ than in $R$. fulgida var. Sullivantii $\left(0.62 \mathrm{~g} \cdot \mathrm{g}^{-1}\right)$ and $M$. didyma $\left(0.78 \mathrm{~g} \cdot \mathrm{g}^{-1}\right)$ (Fig. 2b).

In E. purpurea and $R$. fulgida var. Sullivantii, the relationship of $\psi_{\mathrm{L}}$ to RWC was very similar, as reflected by the slopes of the linear regressions (Fig. 4a). Monarda didyma and H. angustifolius each displayed smaller decreases than E. purpurea or R. fulgida var. Sullivantii in $\psi_{\mathrm{L}}$ as leaf RWC declined (Fig. 4b). At lower leaf RWC, $\psi_{\mathrm{L}}$ in $H$. angustifolius was higher than in the other three species.

The relationship of leaf $\psi_{\mathrm{p}}$ to $\psi_{\mathrm{L}}$ was plotted using data representing $\psi_{\mathrm{L}}$ higher than $-2.10 \mathrm{MPa}$ in $E$. purpurea and $R$. fulgida var. Sullivantii, $-1.60 \mathrm{MPa}$ in $M$. didyma, and $-1.40 \mathrm{MPa}$ in $H$. angustifolius. At $\psi_{\mathrm{L}}$ below the values above, the pressure chamber began to return unrealistically high $\psi_{\mathrm{L}}$ estimates, likely indicative of damage to droughted tissues at high pressurization. Leaf $\psi$ declined with decreasing $\psi_{\mathrm{L}}$ in a similar manner in E. purpurea and R. fulgida var. Sullivantii (similar slopes, Fig. 5a), with $\psi_{\mathrm{p}}$ remain-

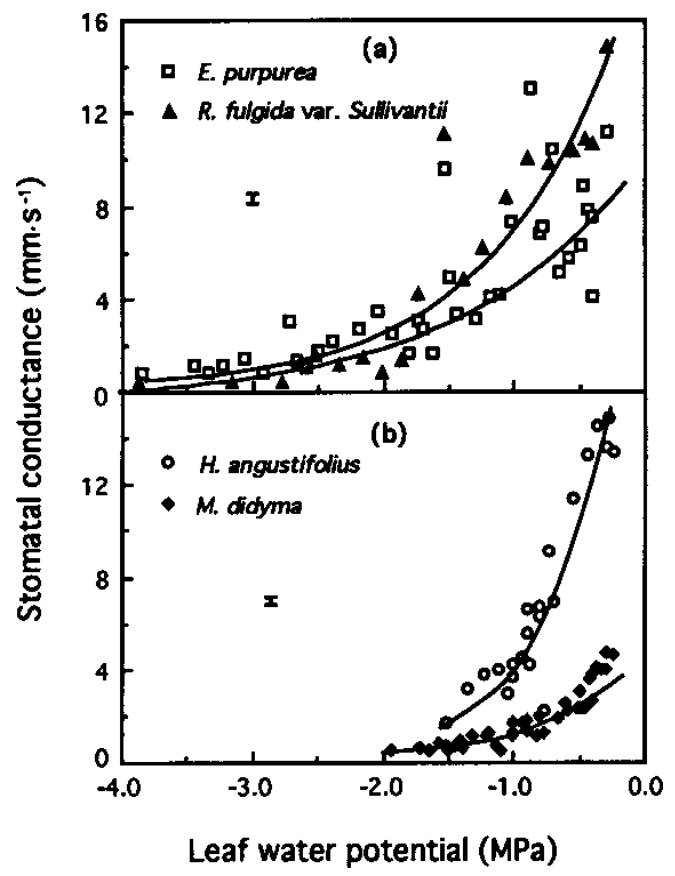

Fig. 1. Stomatal conductance as a function of leaf water potential for (a) Echinacea purpurea $\left[\mathrm{y}=9.64 \times 10^{(0.32 \mathrm{x})}\left(R^{2}=0.59\right)\right]$ and Rudbeckia fulgida var. Sullivantii $[\mathrm{y}$ $\left.=22.65 \times 10^{(0.44 \mathrm{x})}\left(R^{2}=0.56\right)\right]$ and $(\mathbf{b})$ Helianthus angustifolius $\left[\mathrm{y}=20.56 \times 10^{(0.74 \mathrm{x})}\right.$ $\left.\left(R^{2}=0.48\right)\right]$ and Monarda didyma $\left[\mathrm{y}=5.11 \times 10^{(0.61 \mathrm{x})}\left(R^{2}=0.66\right)\right]$. Each symbol represents the mean of four observations. Plots were constructed from individual observations from both drying cycles. Vertical bars $=$ sEs of the means.

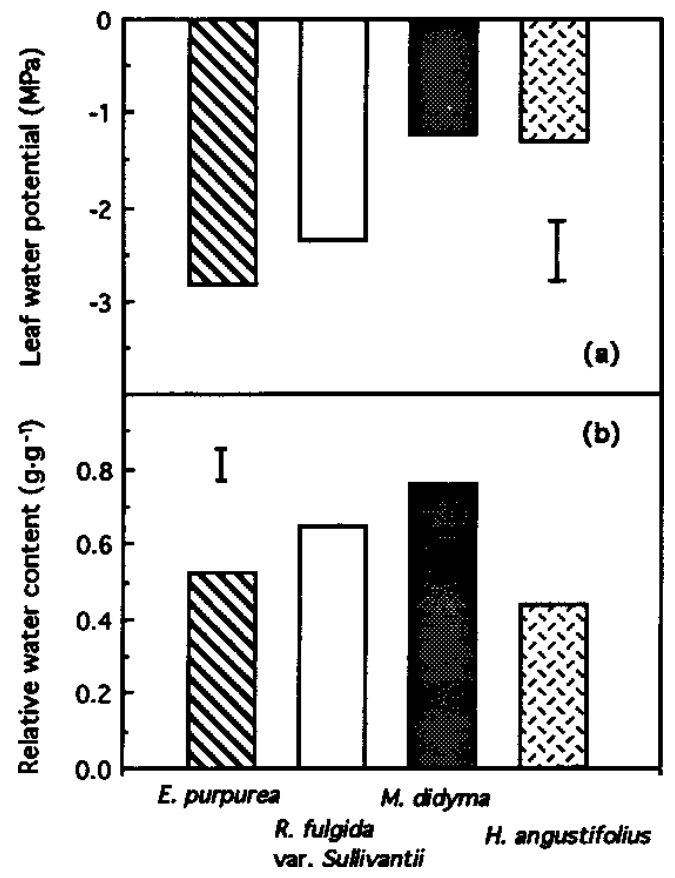

Fig. 2. Mean leaf water potential (a) and leaf relative water content (b) near stomatal closure ( 0.5 to $1.5 \mathrm{~mm} \cdot \mathrm{s}^{-1}$ leaf diffusive conductance) of Echinacea purpurea, Rudbeckia fulgida var. Sullivantii, Monarda didyma, and Helianthus angustifolius. 
ing slightly higher in R. fulgida var. Sullivantii than in E. purpurea at any given $\psi_{\mathrm{L}}$. Leaf water potential at turgor loss $\left(\psi_{\mathrm{p}}{ }^{0}\right)$ values were computed from regressions illustrated in Fig. 5 and represent treatment composites ( sample size $=1$, hence no statistics were computed). The estimated $\psi_{\mathrm{L}}$ at $\psi_{\mathrm{p}}{ }^{0}$ was slightly lower in $R$. fulgida var. Sullivantii $(-2.02 \mathrm{MPa})$ than in E. purpurea $(-1.86 \mathrm{MPa})$. In $M$. didyma, $\psi_{\mathrm{p}}$ at high $\psi_{\mathrm{L}}$ was similar to that of $E$. purpurea (Fig. $5 \mathrm{~b}$ ), and $\psi_{\mathrm{L}}$ at $\psi^{0}$ in $M$. didyma $(-2.05 \mathrm{MPa})$ was similar to that of $R$. fulgida var. Sullivantii. Leaf $\psi$ for $H$. angustifolius was lower than for the other three species at high $\psi_{\mathrm{L}}$, and this trend continued during the drying cycles (Fig. 5b). The estimated $\psi_{\mathrm{L}}$ at $\psi_{\mathrm{p}}{ }^{0}$ in $H$. angustifolius $(-1.71 \mathrm{MPa})$ was highest among the four species.

Leaves of all four species wilted during the drying cycle. Leaves of $H$. angustifolius dried more rapidly (abruptly, after 2 to 3 days) and more severely than those of the other three species. Most leaves of $H$. angustifolius, in contrast to those of the other species, did not recover after rewatering. Leaves of $E$. purpurea and $R$. fulgida wilted gradually during the drying cycle (after $\geq 10$ days of soil drying). Upon rewatering, both species recovered within a few days to one week, and their appearance was respectable; these two species are very rugged, drought-resilient perennials in the landscape (D.S. Chapman, personal observations). Leaves of M. didyma did not wilt until the end of the soil-drying cycles (in both stomatal and lethal experiments). Its physical appearance was least affected by drought compared to the other three species. Like E. purpurea and $R$. fulgida, it recovered within a few days of rewatering.

Dehydration tolerance and osmotic adjustment. Echinacea purpurea had relatively low lethal $\psi_{\mathrm{L}}$ (Fig. 6a) and lethal leaf RWC (Fig. 6c), yet had a high lethal $\psi_{\mathrm{s}}$ (Fig. 6b) and displayed little $\Delta \psi_{\pi}{ }^{100}$ (Fig. 7b). Rudbeckia fulgida var. Sullivantii had low lethal $\psi_{\mathrm{L}}$ (Fig. 6a) and lethal $\psi_{\mathrm{s}}$ (Fig. 6b), displayed a large $\Delta \psi_{\pi}^{100}$ (Fig. 7b), but had a relatively high lethal leaf RWC (Fig. 6c). Monarda

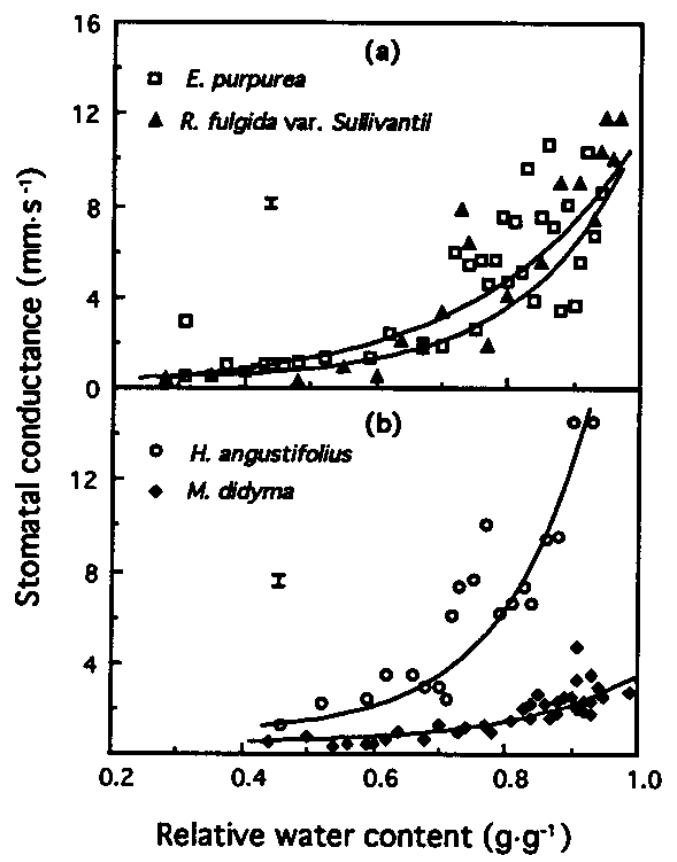

Fig. 3. Stomatal conductance as a function of leaf relative water content for (a) Echinacea purpurea $\left[\mathrm{y}=0.14 \times 10^{(1.83)}\left(R^{2}=0.63\right)\right]$ and Rudbeckia fulgida var. Sullivantii $\left[\mathrm{y}=4.27 \mathrm{e}-2 \times 10^{(2.36 \mathrm{x})}\left(R^{2}=0.57\right)\right]$ and $(\mathbf{b})$ Helianthus angustifolius $\left[\mathrm{y}=0.11 \times 10^{(2.21 \mathrm{x})}\left(R^{2}=0.61\right)\right]$ and Monarda didyma $\left[\mathrm{y}=4.54 \mathrm{e}-2 \times 10^{(1.84 \mathrm{x})}\left(R^{2}\right.\right.$ $=0.60)$ ]. Plots were constructed and regression coefficients computed from individual observations from both drying cycles. Each symbol represents the mean of four observations. Vertical bars $=$ sEs of the means. didyma had a relatively high lethal $\psi_{\mathrm{L}}$ (Fig. 6a) and high lethal leaf RWC (Fig. 6c), yet showed a relatively large $\Delta \psi_{\pi}^{100}$ (Fig. 7b). Helianthus angustifolius had one of the highest lethal $\psi_{\mathrm{L}}$ and little $\Delta \psi_{\pi}^{100}$, yet had a low lethal leaf RWC.

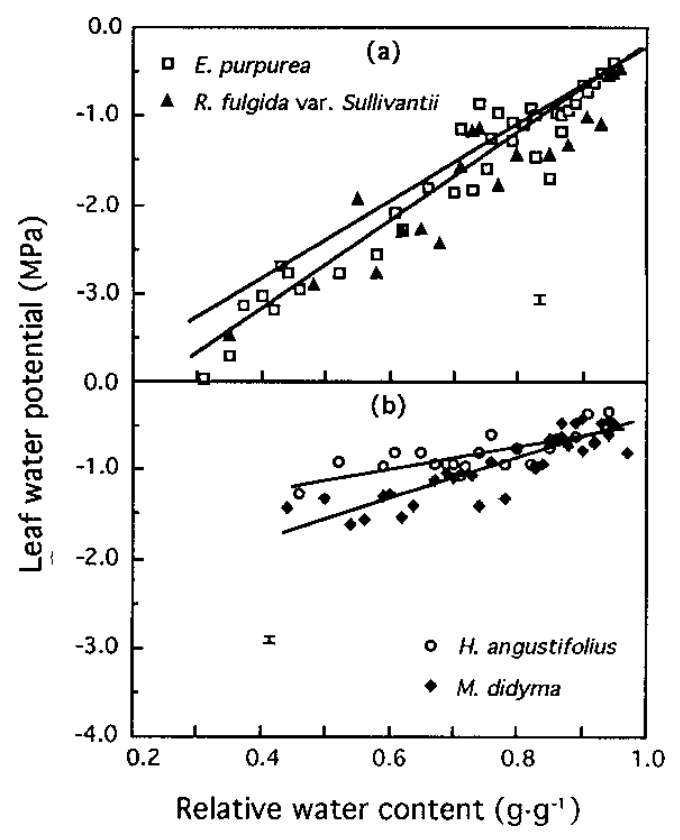

Fig. 4. Leaf water potential as a function of leaf relative water content for (a) Echinacea purpurea $\left[\mathrm{y}=(-5.19)+4.96 \mathrm{x}\left(R^{2}=0.75\right)\right]$ and Rudbeckia fulgida var. Sullivantii $\left[\mathrm{y}=(-4.54)+4.37 \mathrm{x}\left(R^{2}=0.51\right)\right]$ and $(\mathbf{b})$ Helianthus angustifolius $[\mathrm{y}$ $\left.=(-1.77)+1.28 \mathrm{x}\left(R^{2}=0.23\right)\right]$ and Monarda didyma $\left[\mathrm{y}=(-2.56)+2.05 \mathrm{x}\left(R^{2}=\right.\right.$ $0.38)]$. Plots were constructed and regression coefficients computed from individual observations from both drying cycles. Each data symbol represents the mean of four observations. Vertical bars $=$ SES of the means.

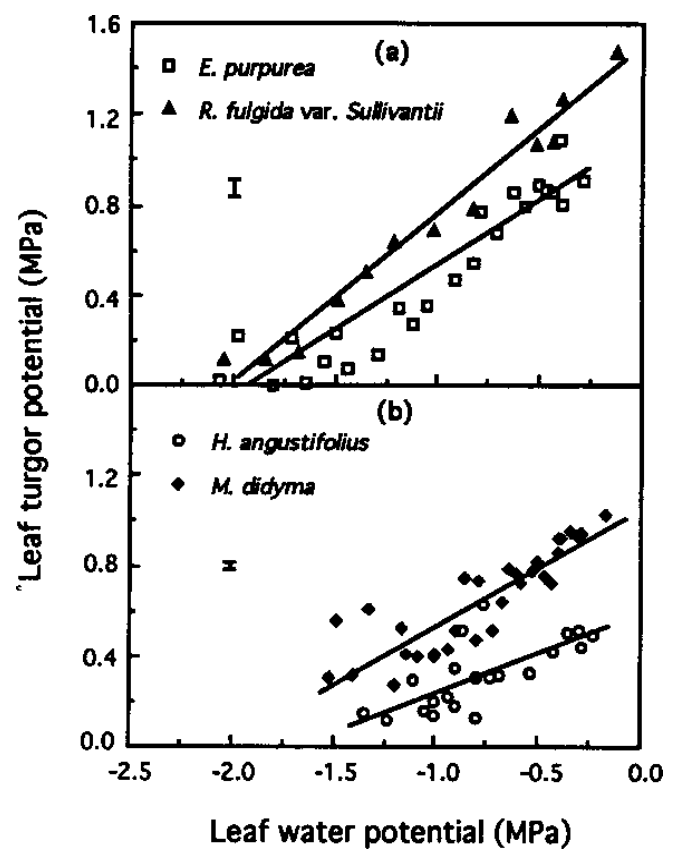

Fig. 5. Leaf turgor potential as a function of leaf water potential for (a) Echinacea purpurea $\left[\mathrm{y}=1.07+0.55 \mathrm{x}\left(R^{2}=0.56\right)\right]$ and Rudbeckia fulgida var. Sullivantii $[\mathrm{y}$ $\left.=1.50+0.74 \mathrm{x}\left(R^{2}=0.83\right)\right]$ and $(\mathbf{b})$ Helianthus angustifolius $\left[\mathrm{y}=0.58+0.34 \mathrm{x}\left(R^{2}\right.\right.$ $=0.19)]$ and Monarda didyma $\left[\mathrm{y}=1.01+0.44 \mathrm{x}\left(R^{2}=0.25\right)\right]$. Plots were constructed and regression coefficients computed from individual observations from both drying cycles. Each data symbol represents the mean of four observations. Vertical bars $=$ SES of the means. 


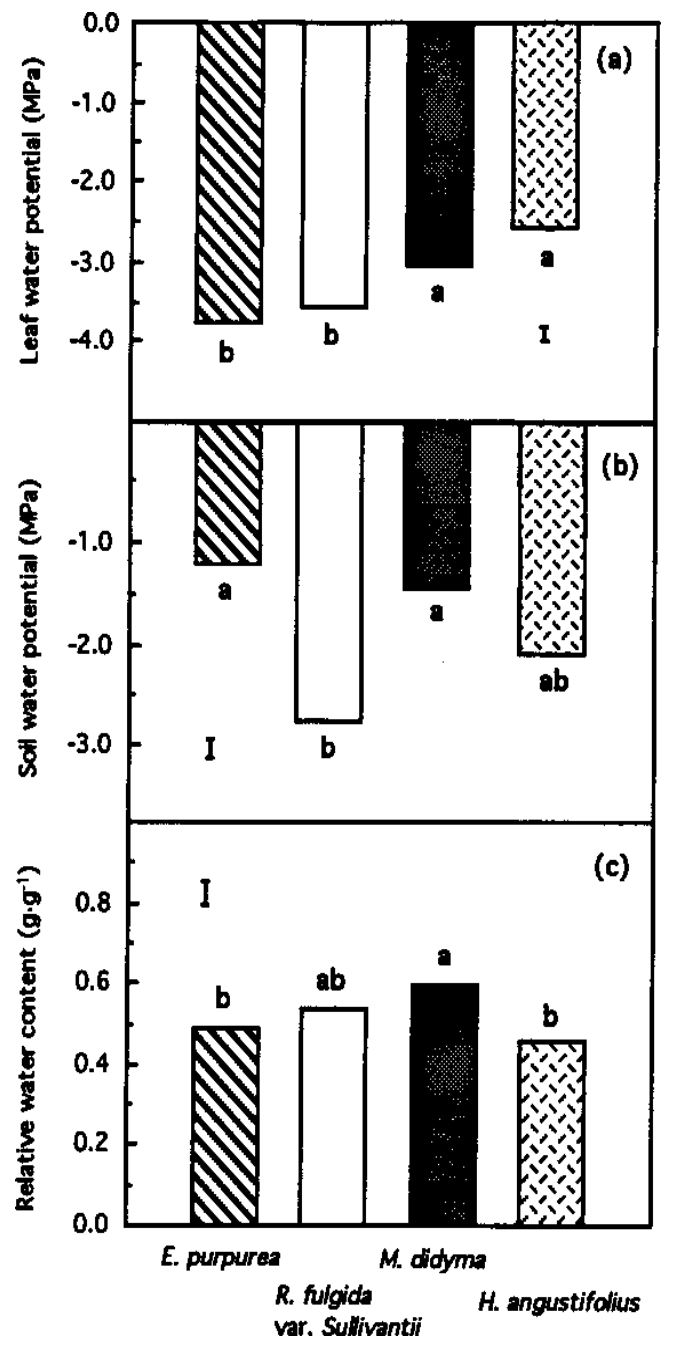

Fig. 6. Lethal leaf water potential (a), lethal soil water potential (b), and lethal leaf relative water content $(\mathbf{c})$ of each species after a prolonged continuous soil drying cycle. Vertical bars $=$ SES of the means; $\mathrm{n}=10$. Mean separation by Duncan's multiple range test, $P \leq 0.05$.

\section{Discussion}

As dehydration tolerance increases (as lethal $\psi_{\mathrm{L}}$ and RWC decline), there is generally a linear decrease in $\psi^{\rightarrow 0}$ (Ludlow, 1989; Ludlow et al., 1983; Sinclair and Ludlow, 1986) and a corresponding increase in the capacity for $\varnothing \psi_{\pi}^{100}$ (Ludlow, 1989; Sheriff et al., 1986; Sinclair and Ludlow, 1985; Wilson et al., 1980). For example, $\psi_{\mathrm{L}}{ }^{\rightarrow 0}$ in five accessions of a drought-tolerant tropical legume, Centrosema, ranged from -5.9 to $-8.0 \mathrm{MPa}$ and had a corresponding lethal $\psi_{\mathrm{L}}$ of -8.0 to $-12.1 \mathrm{MPa}$, whereas $\psi_{\mathrm{L}} \rightarrow 0$ and lethal $\psi_{\mathrm{L}}$ in a drought-avoiding pasture legume, siratro [Macroptilium atropurpureum (DC) Urb.], were -1.9 MPa and 2.4 MPa, respectively (Ludlow et al., 1983). The extremely droughttolerant tropical pasture legume, Galactia striata Urb., exhibited $\Delta \psi_{\pi}^{100}$ up to $2.3 \mathrm{MPa}$, whereas $\Delta \psi_{\pi}{ }^{100}$ in $M$. atropurpureum, was $<0.26 \mathrm{MPa}$ (Sheriff et al., 1986).

Comparisons of the dehydration tolerance (expressed as lethal $\psi_{\mathrm{L}}$ ) of $H$. angustifolius, $M$. didyma, R. fulgida var. Sullivantii, and $E$. purpurea to those of some tropical crops and pasture species ranging from extreme drought avoidance to extreme drought tolerance are shown in Table 1. Relative to the tropical crops and pasture species, the four ornamental perennial species that we

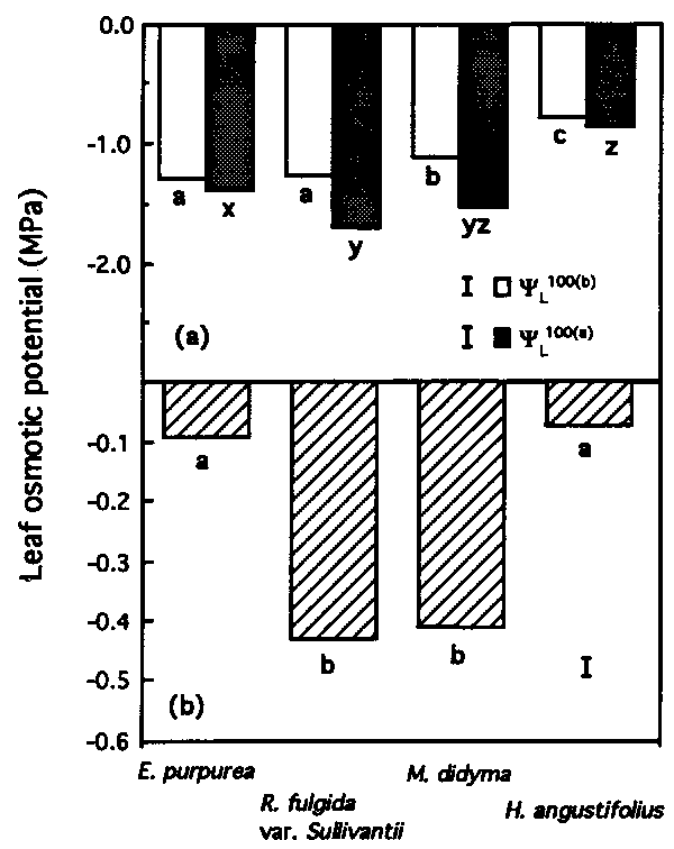

Fig. 7. Leaf osmotic potential at full turgor before $\left(\psi_{\pi}^{100(\mathrm{~b})}\right)$ and after $\left(\psi_{\pi}^{100(\mathrm{a})}\right)$ the drying cycle (a) and leaf osmotic adjustment for each species (b). Vertical bars $=$ SES of the means; $\mathrm{n}=10$. Mean separation by Duncan's multiple range test, $P$ $\leq 0.05$.

investigated are predominantly drought avoiders. Drought-avoidance mechanisms (minimizing water loss and maximizing water uptake) are essential for survival during moderate to severe water deficits because drought avoiders have low dehydration tolerance (high lethal $\psi_{\mathrm{L}}$ and RWC) (Ludlow, 1989; Ludlow et al., 1983; Sinclair and Ludlow, 1986) and display little $\Delta \psi_{\pi}^{100}$ (Ludlow et al., 1985). Most mesophytic species fall into the avoidance category because they close stomata at high $\psi_{\mathrm{L}}$ and RWC to postpone tissue desiccation, having generally evolved in climates where rainless periods are brief (Fitter and Hay, 1987; Levitt, 1980). Stomatal closure is one of the primary defense mechanisms protecting plants from desiccation (Chaves, 1991; Mansfield and Davies, 1981).

In some species, Cs remains relatively constant until a threshold or critical $\psi_{\mathrm{L}}$ or RWC is reached, below which Cs begins to decline (Hsiao, 1973; Ludlow, 1980a, 1980b). In other species, as in the four perennials we investigated, Cs falls in a linear or curvilinear fashion from high $\psi_{\mathrm{L}}$ and RWC (Begg and Turner, 1976). Traditionally, $\psi_{\mathrm{L}}$ has been considered to be the primary parameter controlling stomatal behavior during drought (Beardsell and Cohen, 1975; Ludlow, 1980a), but others (Hsiao, 1973; Turner, 1974) have indicated that stomatal closure was better correlated with leaf $\psi_{\mathrm{p}}^{0}$; recent investigations suggest that stomatal closure is directly linked to soil drying (decreasing $\left.\psi_{\mathrm{s}}\right)($ Bates and Hall, 1981; Gollan et al., 1986). When water stress is moderate to severe, a close correlation between $\psi_{\mathrm{L}}^{\rightarrow 0}$ and $\psi_{\mathrm{L}}$ at $\psi_{\mathrm{p}}{ }^{0}$ frequently exists (Turner et al., 1985; Wilson et al., 1980), but this was not observed in our investigation. In E. purpurea and R. fulgida var. Sullivantii, the estimated $\psi_{\mathrm{L}}$ at $\psi_{\mathrm{p}}{ }^{0}$ was 0.44 to $0.93 \mathrm{MPa}$ higher than $\psi_{\mathrm{L}}{ }^{\rightarrow 0}$ and corresponded more closely to the $\psi_{\mathrm{L}}$ at which Cs leveled off, i.e., stomata remained open for quite awhile after bulk leaf $\psi_{\mathrm{p}}$ reached zero. In $H$. angustifolius and $M$. didyma, the estimated $\psi_{\mathrm{L}}$ at $\psi_{\mathrm{p}}{ }^{0}$ was 0.24 to $0.84 \mathrm{MPa}$ lower than $\psi_{\mathrm{L}}^{\rightarrow 0}$, i.e., stomates closed before bulk leaf $\psi_{\mathrm{P}}$ was lost. These differences may reflect contemporary views of stomatal behavior-that stomata are likely affected by a combination of factors that vary in concert with $\psi_{\mathrm{L}}$ (Chaves, 1991), including leaf $\psi_{\mathrm{p}}$ (Bradford and Hsiao, 1982), $\varnothing \psi_{\pi}{ }^{100}$ (Kaiser, 
Table 1. Dehydration tolerance, expressed as lethal leaf water potential (MPa), of Echinacea purpurea, Rudbeckia fulgida var. Sullivantii, Monarda didyma, and Helianthus angustifolius compared to some tropical crops and pasture species ranging from plants that use the avoidance strategy to those that use the tolerance strategy. Data were obtained from different studies under widely varying conditions. Lethal leaf relative water content (\%) is shown in parentheses and leaf water potential at stomatal closure is shown in brackets. Table adapted from Ludlow (1989).

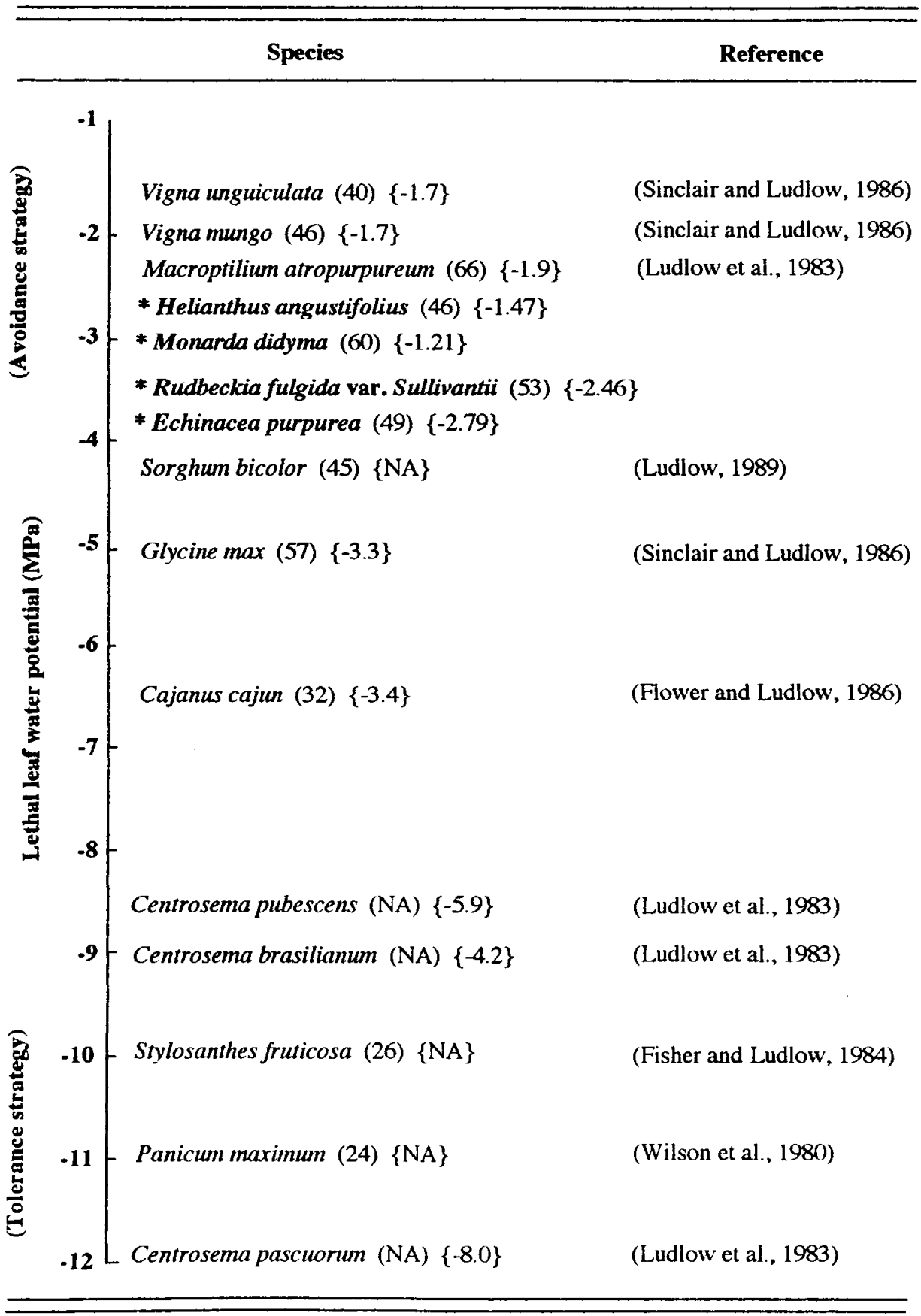

1987), leaf RWC (Boyer, 1989; Sinclair and Ludlow, 1985), leaf epidermal water relations (Tardieu and Davies, 1992), and chemical components coming from the roots (Zhang and Davies, 1989).

Helianthus angustifolius had the most robust drought-avoidance features of the four species we investigated, as demonstrated by its high $\psi_{\mathrm{L}}{ }^{\rightarrow 0}$, high lethal $\psi_{\mathrm{L}}$, and lack of $\Delta \psi_{\pi}{ }^{100}$. Surprisingly, its $\mathrm{RWC}^{\rightarrow 0}$ and lethal RWC were relatively low, features generally found in drought tolerators (Ludlow, 1989). In H. angustifolius, $\psi_{\mathrm{L}}{ }^{\rightarrow 0}$ and lethal $\psi_{\mathrm{L}}$ were similar to those of three drought avoiding legumes-cowpea [Vigna unguiculata (L.) Walp.] (Hall and
Schulze, 1980; Sinclair and Ludlow, 1986), mung bean [Vigna mungo (L.) Hepper] (Ludlow et al., 1985), and M. atropurpureum, (Sheriff et al., 1986), which also demonstrate high $\psi_{\mathrm{L}}^{\rightarrow 0}$ and high lethal $\psi_{\mathrm{L}}$. Deep, extensive root systems (maximizing water uptake) coincide with rapid stomatal closure in some drought avoiders (Markhart, 1985; Sheriff and Ludlow, 1984; Sheriff et al., 1985), providing the plant with a two-fold survival mechanism. The advantage of having these combined avoidance characteristics has been demonstrated by $M$. atropurpureum, which survived longer during drought than the drought-tolerant Centrosema species 
when both plants were grown under the same environmental conditions (Ludlow et al., 1985; Sinclair and Ludlow, 1986). In $H$. angustifolius, the restriction of water loss (i.e., stomatal closure) may not be the primary mechanism of drought avoidance because stomatal closure failed to prevent rapid water loss. We observed severe leaf desiccation in $H$. angustifolius 4 to 7 days after water withholding in the stomatal behavior experiment, whereas leaves of the other three species were not severely wilted until after day 13. We did not investigate root development in our experiment, but it is possible that $H$. angustifolius relies primarily on a deep, extensive root system to maximize water uptake, rather than rapid stomatal closure, to minimize water loss. If this is the case, growing $H$. angustifolius in containers probably increased the rate of tissue desiccation by limiting root development.

The high $\psi_{\mathrm{L}}^{\rightarrow 0}$ and $\mathrm{RWC}^{\rightarrow 0}$, and high lethal $\psi_{\mathrm{L}}$ and $\mathrm{RWC}$ displayed by $M$. didyma were also similar to those found in drought-avoiding legumes (Ludlow et al., 1983; Sinclair and Ludlow, 1986). The extremely low Cs at high $\psi_{\mathrm{L}}$ and the small decreases in Cs with declining $\psi_{L}$ in $M$. didyma are indicative of the conservative role its stomata have in regulating water loss. This feature might indicate that $M$. didyma is exclusively a drought avoider, but its relatively large $\Delta \psi_{\pi}^{100}$ is a feature usually found in drought-tolerant species (Flower and Ludlow, 1986; Hsiao et al., 1984). Among the four species in our investigation, E. purpurea had the greatest dehydration tolerance in terms of $\psi_{\mathrm{L}} \rightarrow 0, \mathrm{RWC}^{\rightarrow 0}$, lethal $\psi_{\mathrm{L}}$, and lethal RWC, but displayed little $\Delta \psi_{\pi}^{100}$. The relatively low $\psi_{\mathrm{L}}{ }^{\rightarrow 0}$, low lethal $\psi_{\mathrm{L}}$, and large $\Delta \psi_{\pi}^{100}$ found in $R$. fulgida var. Sullivantii reflect some degree of drought tolerance, but its lethal RWC was higher than those of a few extreme drought avoiders (Sinclair and Ludlow, 1986). Lethal $\psi_{\mathrm{L}}$ in E. purpurea and R. fulgida var. Sullivantii was similar to that of Sorghum bicolor (L.) Moench, which has a slightly lower $\psi_{\mathrm{L}}$, yet is considered to be a drought avoider because it displays little $\Delta \psi_{\pi}{ }^{100}$ (Ludlow, 1989).

Leaf $\Delta \psi_{\pi}^{100}$ is defined as the lowering of the tissue osmotic potential arising from the net active accumulation of solutes in cells (vs. passive accumulation from decreases in cell volume) in response to water deficits and salinity (Turner and Jones, 1980). Leaf $\Delta \psi_{\pi}^{100}$ assists in turgor maintenance, which sustains stomatal opening (stomatal adjustment) and hence allows photosynthesis and leaf expansion to continue during periods of water stress (Hsiao, 1973; Ludlow et al., 1985). However, $\Delta \psi_{\pi}^{100}$ seems to be as important to plant survival as it is to maintaining $\psi_{\mathrm{p}}$ (Flower and Ludlow, 1986; Hsiao et al., 1984). A linear relationship between dehydration tolerance (lethal $\psi_{L}$ ) and $\Delta \psi_{\pi}^{100}$ frequently exists when comparing these parameters among a wide range of species (drought avoiders to drought tolerators) (Ludlow, 1989; Sinclair and Ludlow, 1986), but this is not always the case when considering only a few species (Bjorkman et al., 1980; O'Neill, 1983), as demonstrated by $M$. didyma and $E$. purpurea in our experiment. Generally, a linear relationship would be expected, since a drought avoider (low dehydration tolerance) with high $\Delta \psi_{\pi}^{100}$ would die from dehydration unless the plant had exceptionally deep roots, as in phreatophytes (Ludlow, 1989). There was a consistent linear relationship between $\psi_{\mathrm{L}}{ }^{\rightarrow 0}$ and lethal $\psi_{\mathrm{L}}$ among the four species we investigated, a result that complies with that found among a wide range of species (Ludlow, 1989; Sinclair and Ludlow, 1986). A linear relationship between lethal $\psi_{\mathrm{L}}$ and lethal RWC can also be found (Ludlow, 1989), but, among the species we investigated, this was not the case. Lethal leaf RWC in H. angustifolius was lower than those of the more drought-tolerant species, $R$. fulgida var. Sullivantii and M. didyma. A similar situation was observed in $V$. unguiculata and $V$. mungo, which died at a high $\psi_{\mathrm{L}}$ but at lower lethal RWC than the more drought-tolerant soybean [Glycine max (L.) Merr.] (Sinclair and Ludlow, 1986). Therefore, as in $\Delta \psi_{\pi}^{100 /}$ lethal $\psi_{\mathrm{L}}$, the linear relationship in lethal $\psi_{\mathrm{L}}$ /lethal RWC becomes more evident when comparing values among a wide range of species. Recently, it was suggested that lethal RWC is a more precise measure of dehydration tolerance than lethal $\psi_{\mathrm{L}}$ because a particular species dies within a smaller range of lethal RWC (Flower and Ludlow, 1986).

Our results were from plants growing in containers in a controlled environment, but dehydration tolerance, $\psi_{\mathrm{L}} \rightarrow 0$, and $\mathrm{RWC}^{\rightarrow 0}$ can vary with growing conditions. Generally, stomata in fieldgrown plants are not as sensitive to decreases in $\psi_{\mathrm{L}}$. Stomata in creosote bush (Larrea divaricata Cav.), a drought-tolerant desert shrub, closed at $-4.0 \mathrm{MPa}$ when grown in a controlled environment in containers and at $-5.8 \mathrm{MPa}$ when grown in the field. In the drought-avoiding faba bean (Vicia faba L.), the same values were -0.6 and $-1.0 \mathrm{MPa}$, respectively (Fitter and Hay, 1987). Therefore, it is likely that we would find a different set of values for the parameters we measured under field conditions.

Variations in drought resistance (dehydration tolerance and the mechanisms involved) generally correspond to the natural range of the species (Ludlow et al., 1983). We might expect to find a stronger expression of drought avoidance in species like $H$. angustifolius and $M$. didyma because they have evolved in microclimates close to water and in temperate climates with frequent rainfall. In contrast, E. purpurea and $R$. fulgida var. Sullivantii have evolved in dry, open microclimates, and, in the case of $E$. purpurea, a prairie species, in a climate with significant fluctuations in rainfall. As a result, E. purpurea and $R$. fulgida var. Sullivantii have combined some degree of dehydration tolerance with moderate avoidance responses. This combination may provide plants with a capacity to survive a wide range of environments (Ludlow, 1989).

Moisture stress is one of the major causes of losses in plant quality after wholesale production (Nelson and Carlson, 1987). Understanding a plant's drought resistance may help growers and landscapers to select and develop cultural methods that correspond to the specific mechanisms of the plant. These cultural methods could effectively minimize water stress after wholesale production.

\section{Literature Cited}

Ackerson, R.C. and R.R. Hebert. 1980. Osmoregulation in cotton in response to water stress: Alteration in photosynthesis, leaf conductance, translocation, and ultrastructure. Plant Physiol. 67:484-488.

Bates, L.M. and A.E. Hall. 1981. Stomatal closure with soil water depletion not associated with changes in bulk leaf water status. Oecologia 50:62-65.

Beardsell, M.F. and D. Cohen. 1975. Relationship between leaf water status, abscisic acid levels, and stomatal resistance in maize and sorghum. Plant Physiol. 56:207-212.

Begg, J.E. 1980. Morphological adaptations of leaves to water stress, p. 33-42. In: N.C. Turner and P.J. Kramer (eds.). Adaptation of plants to water and high temperature stress. Wiley Interscience, New York.

Begg, J.E. and N.C. Turner. 1976. Crop water deficits. Adv. Agron. 28:161-217.

Bjorkman, O., W.J.S. Downton, and H.A. Mooney. 1980. Response and adaptation to water stress of Nerium oleander. Carnegie Inst. of Washington Yearbook 79:150-157.

Boyer, J.S. 1989. Water potential and plant metabolism: Comments on P.J. Kramer's article Changing concepts regarding plant water relations and J.B. Passioura's response. Plant Cell Environ. 12:213-216.

Bradford, K.J. and T.C. Hsiao. 1982. Physiological responses to moderate water stress, p. 246-324. In: O.L. Lange, P.S. Nobel, C.B. Osmond, and H. Ziegler (eds.). Encyclopedia of plant physiology: Physiological plant ecology. II. Water relations and carbon assimilation. Springer-Verlag, 
Berlin.

Chaves, M.M. 1991. Effects of water deficits on carbon assimilation. J. Expt. Bot. 42:1-16.

Fisher, M.J. and M.M. Ludlow. 1984. Adaptation to water deficits in Stylosanthes, p. 163-179. In: H.M. Stace and L.A. Edye (eds.). The biology and agronomy of Stylosanthes. Academic Press, Sydney.

Fitter, A.H. and R.K.M. Hay. 1987. Environmental physiology of plants. Academic Press, San Diego.

Flower, D.J. and M.M. Ludlow. 1986. Contribution of osmotic adjustment to the dehydration tolerance of water-stressed pigeonpea [Cajanus cajun (L.) Millsp.] leaves. Plant Cell Environ. 9:33-40.

Gollan, T., J.B. Passioura, and R. Munns. 1986. Soil water status affects the stomatal conductance of fully turgid wheat and sunflower leaves. Austral. J. Plant Physiol. 13:459-464.

Hall, A.E. and E.-D. Schulze. 1980. Drought effects on transpiration and leaf water status of cowpea in controlled environments. Austral. J. Plant Physiol. 7:141-147.

Hsiao, T.C. 1973. Plant responses to water stress, p. 519-570 In: W.R. Briggs, P.C. Green, and R.L. Jones (eds.). Annu. Rev. Plant Physiol. vol. 24. Annual Reviews, Palo Alto, Calif.

Hsiao, T.C., J.C. O’Toole, E.B. Yambao, and N.C. Turner. 1984. Influence of osmotic adjustment on leaf rolling and tissue death in rice (Oryza sativa L.). Plant Physiol. 75:338-341.

Kaiser, W.M. 1987. Effects of water deficit on photosynthetic capacity. Physiol. Plantarum 71:142-149.

Kummerow, J. 1980. Adaptation of roots in water-stressed native vegetation, p. 57-73. In: N.C. Turner and P.J. Kramer (eds.). Adaptation of plants to water and high temperature stress. Wiley Interscience, New York.

Levitt, J. 1980. Responses of plants to environmental stress. vol. 2. Academic Press, New York.

Ludlow, M.M. 1980a. Adaptive significance of stomatal response to water stress, p. 123-138. In: N.C. Turner and P.G. Kramer (eds.). Adaptation of plants to water and high temperature stress. Wiley Interscience, New York.

Ludlow, M.M. 1980b. Stress physiology of tropical pasture plants. Trop. Grassland 14:136-145.

Ludlow, M.M. 1989. Strategies in response to water stress, p. 269-281. In: H.K. Kreeb, H. Richter, and T.M. Hinkley (eds.). Structural and functional response to environmental stresses: Water shortage. SPB Academic Press, The Netherlands.

Ludlow, M.M., A.C.P. Chu, R.J. Clements, and R.G. Kerslake. 1983. Adaptation of species of Centrosema to water stress. Austral. J. Plant Physiol. 10:119-130.

Ludlow, M.M., M.J. Fisher, and J.R. Wilson. 1985. Stomatal adjustment to water deficits in three tropical grasses and a tropical legume grown in controlled conditions and in the field. Austral. J. Plant Physiol. 12:131149.

Ludlow, M.M. and K. Ibaraki. 1979. Stomatal control of water loss in siratro [Macroptilium atropurpureum (DC) Urb.], a tropical pasture legume. Ann. Bot. 43:639-647.

Mansfield, T.A. and W.J. Davies 1981. Stomata and stomatal mechanisms, p. 315-346. In: D. Aspinall and L.G. Paleg (eds.). Physiology and biochemistry of drought resistance. Academic Press, Sydney.

Markhart, A.H. 1985. Comparative water relations of Phaseolus vulgaris L. and Phaseolus acutifolius Gray. Plant Physiol. 77:113-117.

McWilliam, J.R. 1986. The national and international importance of drought and salinity effects on agricultural production. Austral. J. Plant Physiol. 35:1-13.

Morgan, J.M. 1980. Differences in adaptation to water stress within crops, p. 369-382. In: N.C. Turner and P.J. Kramer (eds.). Adaptation of plants to water and high temperature stress. Wiley Interscience, New York.

Nagarajah, S. and E.-D. Shulze. 1983. Responses of Vigna unguiculata (L.) Walp. to atmospheric and soil drought. Austral. J. Plant Physiol. 10:384-394.

Nelson, L. and W. Carlson. 1987. Improve the marketability of bedding plants. Greenhouse Grower 5:84-85.

Nobel, P.S. 1977. Water relations and photosynthesis of barrel cactus. Oecologia 27:117-133.

O'Neill, O.D. 1983. Role of osmotic potential gradients during water stress and leaf senescence in Fragaria virginiana. Plant Physiol. 72:931-937.

Oosterhuis, D.M. and S.D. Wullschleger. 1987. The use of leaf discs in thermocouple psychrometers for measurement of water potential. Proc. Intl. Conf. Measurement Soil Plant Water Status. vol. 2. Utah State Univ., Logan, 6-10 July.

Radford, A.E., H.E. Ahles, and C.R. Bell. 1968. Manual of the vascular flora of the Carolinas. Univ. of North Carolina Press, Chapel Hill.

Sheriff, D.J. and M.M. Ludlow. 1985. Diaheliotropic responses of leaves of Macroptilium atropurpureum cv. Siratro. Austral. J. Plant Physiol. 12:151-171.

Sheriff, D.W., M.J. Fisher, G. Rusitzka, and C.W. Ford. 1986. Physiological reactions to an imposed drought by two twining pasture legumes: Macroptilium atropurpureum (desiccation sensitive) and Galactia striata (desiccation insensitive). Austral. J. Plant Physiol. 13:431-445.

Sinclair, T.R. and M.M. Ludlow. 1985. Who taught plants the thermodynamics of water? The unfulfilled potential of plant water potential. Austral. J. Plant Physiol. 12:213-217.

Sinclair, T.R. and M.M. Ludlow. 1986. Influence of soil water supply on the plant water balance of four tropical grain legumes. Austral. J. Plant Physiol. 13:329-341.

Tardieu, F. and W.J. Davies. 1992. Stomatal response to abscisic acid is a function of current plant water status. Plant Physiol. 98:540-545.

Turk, K.J., A.E. Hall, and C.W. Asbell. 1980. Drought adaptations of cowpea I. Influence of drought in seed yield. Agron J. 72:413-420.

Turner, N.C. 1974. Stomatal behavior and water status of maize, sorghum, and tobacco under field conditions. II. At low water potential. Plant Physiol. 53:360-365.

Turner, N.C. and M.M. Jones. 1980. Turgor maintenance by osmotic adjustment: a review and evaluation, p. 87-103. In: N.C. Turner and P.J. Kramer (eds.). Adaptation of plants to water and high temperature stress. Wiley Interscience, New York.

Turner, N.C. and P.J. Kramer. 1980. Adaptation of plants to water and high temperature stress. N.C. Turner and P.J. Kramer (eds.). Wiley Interscience, New York. p. ix-x. (Intro.)

Turner, N.C., E.-D. Shulze, and T. Gollan. 1985. The responses of stomata and leaf gas exchange to vapor pressure deficits and soil water content. Oecologia 65:348-355.

Wilson, J.R., M.M. Ludlow, M.J. Fisher, and E.-D. Shulze. 1980. Adaptation to water stress of the leaf water relations of four tropical forage species. Austral. J. Plant Physiol. 7:207-220.

Zhang, J. and W.J. Davies. 1989. Abscisic acid produced in dehydrating roots may enable the plant to measure the water status of the soil. Plant Cell Environ. 12:73-81. 